\title{
CpG oligodeoxynucleotide ligand potentiates the activity of the pVAX1-Sj26GST
}

\author{
JUN LU ${ }^{1}$, SHAN JIANG ${ }^{2}$, SONG YE $^{1}$, YUN DENG $^{1}$, SHUAI MA ${ }^{1}$ and CHAO-PIN LI $^{3}$ \\ ${ }^{1}$ Department of Pathogen Biology and Immunology, School of Medicine, Anhui University of Science and Technology; \\ ${ }^{2}$ Department of Mining Engineering, Huainan Vocational and Technical College, Huainan, Anhui 232001; \\ ${ }^{3}$ Department of Pathogen Biology, Bengbu Medical College, Wuhu, Anhui 241002, P.R. China
}

Received February 22, 2013; Accepted April 17, 2013

DOI: 10.3892/br.2013.99

\begin{abstract}
Schistosomiasis is considered one of the most important neglected tropical diseases and remains a major public health problem in endemic countries. Toll-like receptor (TLR) ligands have been investigated as potential vaccine adjuvants for tumor and virus immunotherapy. However, few TLR ligands affecting schistosoma vaccines have been characterized. In this study, we evaluated a TLR9 ligand (CpG oligodeoxynucleotide 1826, CpG) as an adjuvant for a partially protective DNA vaccine encoding a 26-kDa glutathione S-transferase of Schistosoma japonicum (pVAX1-Sj26GST). Vaccination with pVAX1-Sj26GST in combination with $\mathrm{CpG}$ inhibited Treg immunosuppressive function, upregulated the production of interferon (IFN)- $\gamma$, tumor necrosis factor (TNF)- $\alpha$, interleukin (IL)-4, IL-10, IL-2 and IL- 6 , and decreased $\mathrm{CD}^{+}{ }^{+} \mathrm{CD} 8{ }^{+} \mathrm{Foxp}^{+}{ }^{+}$expression in vitro, which may contribute to the escape from Treg-mediated suppression during vaccination, allowing expansion of antigen-specific $\mathrm{T}$ cells against pathogens. In conclusion, our data demonstrated that selective TLR ligand combination may increase protective efficacy against schistosomiasis, which may synergistically antagonize Treg-mediated suppression.
\end{abstract}

\section{Introduction}

Schistosomiasis is considered one of the most important neglected tropical diseases and remains a major public health problem in endemic countries $(1,2)$. Although schistosomiasis may be effectively treated with praziquantel (3), the high reinfection rate limits its overall success and repeated

Correspondence to: Dr Jun Lu, Department of Pathogen Biology and Immunology, School of Medicine, Anhui University of Science and Technology, 25 Dongshanzhong Road, Huainan, Anhui 232001, P.R. China

E-mail: cfdxlujun@126.com

Key words: CpG oligodeoxynucleotide ligand, pVAX1-Sj26GST, vaccine administration is often required multiple times during the first two decades $(4,5)$. Therefore, the development of a safe and effective vaccine may improve the long-term treatment of schistosomiasis and the efficacy of chemotherapeutic interventions (6,7). Despite decades of research towards the development of vaccines against Schistosoma japonicum (S.japonicum), however, the current schistosoma vaccine only induces limited protection, the reasons for which have not yet been elucidated.

A potential factor limiting the response of the immune system to vaccination is the presence of regulatory $\mathrm{T}$ cells (Tregs) which suppress T-cell activation $(8,9)$. Previous studies demonstrated that Tregs dampen the immune response against the pathogen in rats harboring $S$. japonicum $(10,11)$. Toll-like receptors (TLRs) are mediators of innate immune responses detecting conserved pathogen-associated molecules. Thus, selecting the optimal TLR ligands for a given vaccine may prove to be a crucial component in maximizing the anti-pathogen immune response. However, few TLR ligands affecting the schistosome vaccine have been characterized thus far (12).

In the present study, we investigated whether the pVAX1-Sj26GST vaccine in combination with the CpG oligodeoxynucleotide (ODN) 1826 (CpG) conferred an improved immune response against $S$. japonicum and assessed the impact of these TLR ligands on the regulatory function of Tregs in vitro. It was observed that pVAX1-Sj26GST vaccination combined with $\mathrm{CpG}$ led to the detection of higher levels of interferon (IFN)- $\gamma$ and tumor necrosis factor (TNF)- $\alpha$ in the supernatant of splenocytes and improved the protection against $S$.japonicum. $\mathrm{CpG}$ inhibited Treg immunosuppressive function and upregulated the production of IFN- $\gamma$, TNF- $\alpha$, interleukin (IL)-4, IL-10, IL-2 and IL-6 in vitro, which may contribute to the escape from Treg-mediated suppression during vaccination, allowing expansion of antigen-specific $\mathrm{T}$ cells against pathogens. Immunization combined with the CpG TLR ligand therefore is a promising novel approach in the design of schistosome vaccines.

\section{Materials and methods}

Animals. Six-week-old C57BL/6 female rats were provided by the Center of Experimental Animals (Nanjing University, 
Nanjing, China) and bred in university facilities. The animal experiments were performed in accordance with the Chinese laws for animal protection and in adherence to experimental guidelines and procedures approved by the Institutional Animal Care and Use Committee (IACUC) and the Ethics Review Committee of Nanjing Medical University for the use of laboratory animals (permit no. NJMU 09-1107). Oncomelania hupensis (Chinese mainland snail strain) harboring S. japonicum cercariae were purchased from the Jiangsu Institute of Parasitic Diseases (Wuxi, China).

Reagents. The TLR9 ligand $\mathrm{CpG}$, with a nuclease-resistant phosphorothioate backbone and no detectable endotoxin, was purchased from the Coley Pharmaceutical Group (Wellesley, MA, USA). The sequence of CpG was 5'-TCCATGACGTTCCT GACGTT-3'. Soluble schistosome worm antigen was prepared as previously described $(13,14)$. pVAX1-Sj26GST was purchased from the Institute of Parasitic Diseases (Nanjing University, Nanjing, China).

Immunization infection. In each experiment, C57BL/6 rats were divided into seven groups (n=8/group). Each rat was intramuscularly injected with pVAX1-Sj26GST $(50 \mu \mathrm{g})$, with or without $\mathrm{CpG}(25 \mu \mathrm{g})$. Immunization was repeated three times at 14-day intervals. Two weeks after the final vaccination, all the rats from each group were challenged percutaneously with $40 \pm 1 S$. japonicum cercariae. After six weeks, rats were sacrificed and perfused to determine the adult worm and liver egg burdens. Reductions in worm/liver egg burdens were expressed as the percentage of the burden recorded in the control groups.

Cell isolation and culture. Single-cell suspensions were prepared by teasing apart spleens, inguinal and mesenteric lymph nodes from 6 rats/group in PBS containing $1 \%$ FCS and $1 \%$ EDTA, followed by red blood cell lysis with Tris-ammonium chloride buffer. $\mathrm{CD}^{+} \mathrm{T}$ cells were purified from single-cell suspensions with a $\mathrm{CD} 4^{+} \mathrm{T}$ Cell Negative-Isolation kit (Miltenyi Biotec, Auburn, CA, USA) and a magnetic-activated cell sorter, according to the manufacturer's recommendations $\left(>97 \% \mathrm{CD}^{+} \mathrm{T}\right.$ cells by flow cytometric analysis).

$\mathrm{CD} 4{ }^{+} \mathrm{CD} 25^{+}$and $\mathrm{CD} 4{ }^{+} \mathrm{CD} 25^{-}$cell populations were separated from purified $\mathrm{CD} 4^{+} \mathrm{T}$ cells using a mouse regulatory $\mathrm{T}$ Cell Isolation kit (Miltenyi Biotec), according to the manufacturer's protocol. The $\mathrm{CD} 25^{+}$populations were $>95 \%$ $\mathrm{CD} 4{ }^{+} \mathrm{CD} 25^{+}$and the $\mathrm{CD} 4{ }^{+} \mathrm{CD} 25$ populations were $98 \%$ pure, as determined by flow cytometry. $\mathrm{CD} 4{ }^{+} \mathrm{CD} 25^{+}$cells were cultured in 96-well U-bottom plates with $1 \times 10^{5}$ antigen-presenting cells (APCs)/well in triplicate for $72 \mathrm{~h}$ at $37^{\circ} \mathrm{C}$ in complete RPMI-1640 medium $(0.2 \mathrm{ml} /$ well). Cultures were stimulated with $1 \mathrm{~g} / \mathrm{ml}$ soluble anti-CD3 (BD Pharmingen, Inc., San Diego, CA, USA) in the presence or absence of $3 \mu \mathrm{g} / \mathrm{ml} \mathrm{CpG}$. Proliferation was measured by incubating with $0.5 \mu \mathrm{Ci} /$ well of ${ }^{3} \mathrm{H}$-thymidine and measuring incorporation during the final $16 \mathrm{~h}$ of a 3 -day culturing period. The supernatants were collected and quantified for IFN- $\gamma$, TNF- $\alpha$, IL-4, IL-10, IL-2 and IL-6 production using the FlowCytomix Mouse Cytokine kit (Bender MedSystems, Vienna, Austria) according to the manufacturer's instructions.

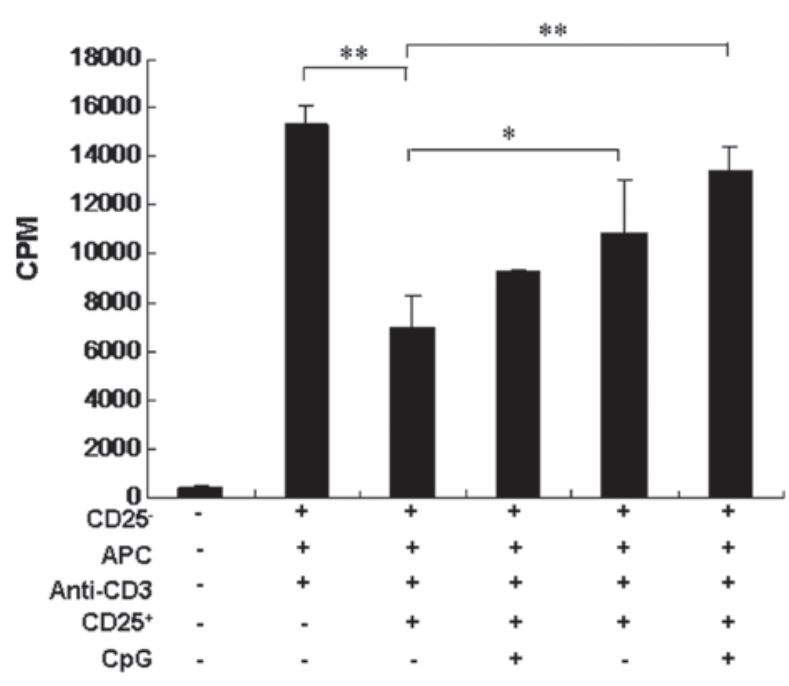

Figure 1. Combination with $\mathrm{CpG}$ inhibited the $\mathrm{CD} 4^{+} \mathrm{CD} 25^{+}$Treg function in vitro. Isolated $\mathrm{CD} 4^{+} \mathrm{CD} 25^{-} \mathrm{T}$ cells $\left(1 \times 10^{5} /\right.$ well $)$ from naïve rats were cultured with or without $\mathrm{CD} 4^{+} \mathrm{CD} 25^{+}$Tregs $\left(5 \times 10^{4} /\right.$ well $)$, irradiated antigen-presenting cells (APCs) (1x10 $/$ well) and $1 \mu \mathrm{g} / \mathrm{ml}$ anti-CD3 in 96-well plates in the presence or absence of $3 \mu \mathrm{g} / \mathrm{ml} \mathrm{CpG}$ for $72 \mathrm{~h}$. Proliferation was determined by measuring ${ }^{3} \mathrm{H}$-thymidine incorporation during the last $16 \mathrm{~h}$ of the experiment. Data are expressed as means \pm standard deviation of three independent experiments performed in triplicate. ${ }^{*} \mathrm{P}<0.05 ;{ }^{* *} \mathrm{P}<0.01$.

Flow cytometry. The Mouse Regulatory T Cell Staining kit (eBioscience, San Diego, CA, USA) was used for the analysis of $\mathrm{CD}^{+}{ }^{+} \mathrm{CD} 25^{+} \mathrm{Foxp}^{+} \mathrm{T}$ cells. Splenocytes from immunized or naïve rats, in the presence or absence of $\mathrm{CpG}(3 \mu \mathrm{g} / \mathrm{ml})$ for $48 \mathrm{~h}$, were surface-stained with PerCP anti-CD3 monoclonal antibody (eBioscience), FITC anti-CD4 mAbs and APC anti-CD25 mAbs, followed by fixation and permeabilization with Cytofix/Cytoperm and were then stained intracellularly with phycoerythrin mouse anti-Foxp3 immunoglobulin control antibody, according to the manufacturer's protocol. Data were collected on a FACSCalibur flow cytometer (BD Biosciences, Franklin Lakes, NJ, USA) and analyzed with FlowJo software (Tree Star, San Carlos, CA, USA).

Statistical analysis. Data were expressed as the means \pm standard deviation. Statistical analysis was performed using SPSS software version 12.0 (SPSS Inc., Chicago, IL, USA). Statistical significance was determined by the Student's t-test and $\mathrm{P}<0.05$ was considered to indicate a statistically significant difference.

\section{Results}

Cp G inhibits $C D 4^{+} C D 25^{+}$Treg function in vitro. TLR9 ligands have been shown to directly impair Treg function in humans or rats $(15,16)$. To investigate the effects of $\mathrm{CpG}$ and $\mathrm{R} 848$ on Treg activity in our series, $\mathrm{CD} 4^{+} \mathrm{CD} 25^{-} \mathrm{T}$ cells (responder cells) were sorted and co-cultured with $\mathrm{CD} 4{ }^{+} \mathrm{CD} 25^{+} \mathrm{T}$ cells from naïve rats. The results shown in Fig. 1 demonstrate that, following stimulation with anti-CD3 antibody, $\mathrm{CD} 4{ }^{+} \mathrm{CD} 25^{+} \mathrm{T}$ cells were highly effective in suppressing the $\mathrm{CD} 4^{+} \mathrm{CD} 25^{-} \mathrm{T}$-cell proliferation. Conversely, the addition of $\mathrm{CpG}$ significantly inhibited Treg function (Fig. 1). These results suggest that the combination with $\mathrm{CpG}$ reduces Treg frequency in vaccinated rats in vivo and inhibits Treg function in vitro. 
A

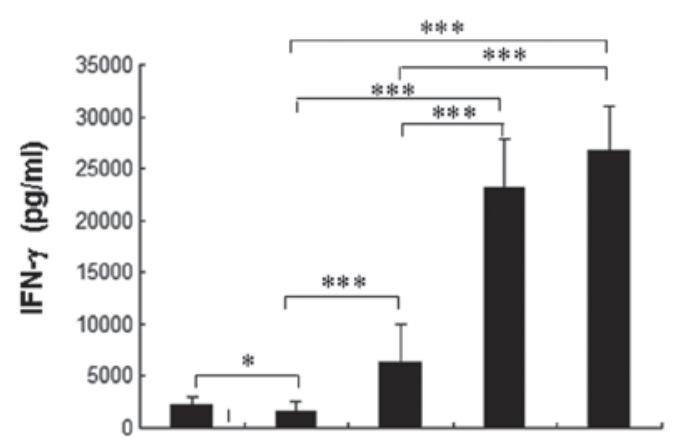

C

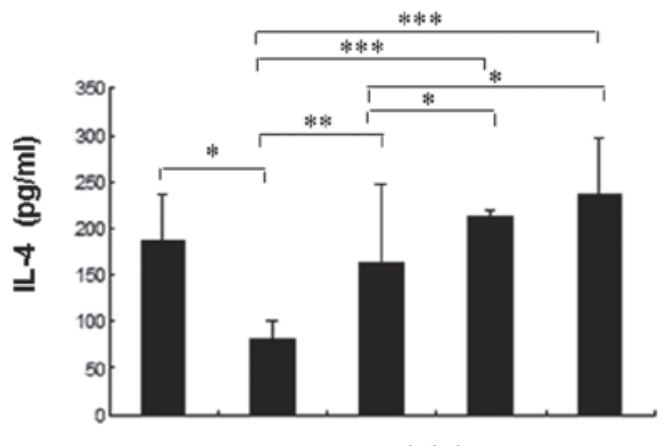

E

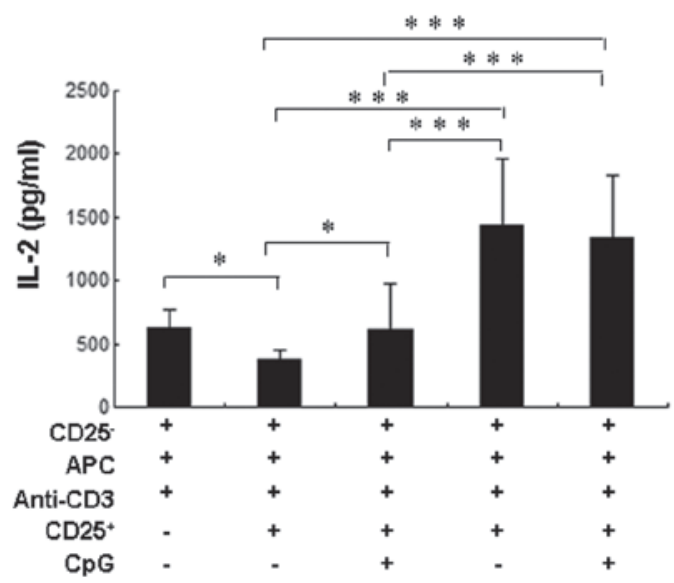

B

D
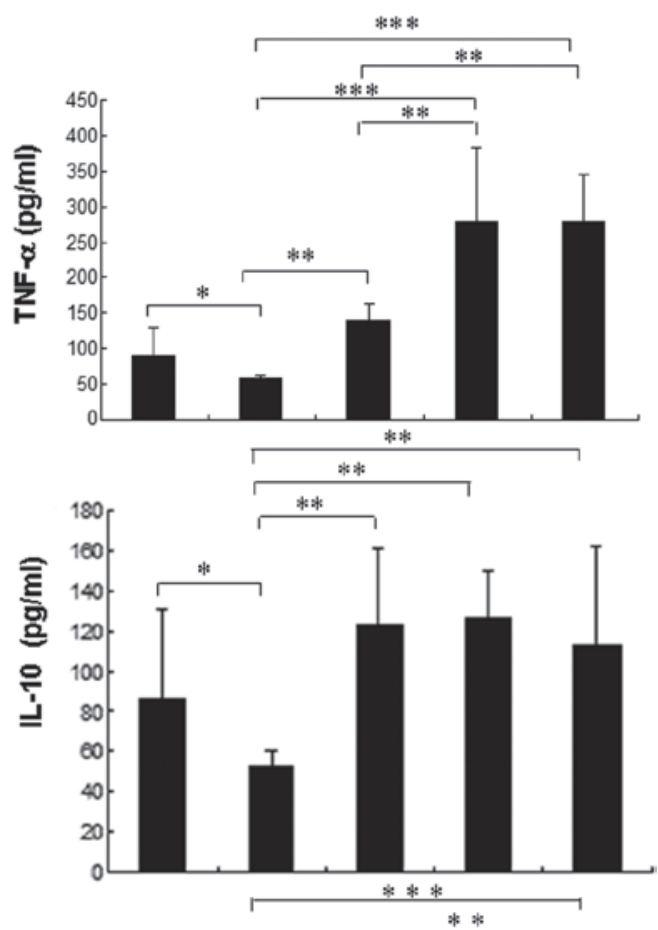

F

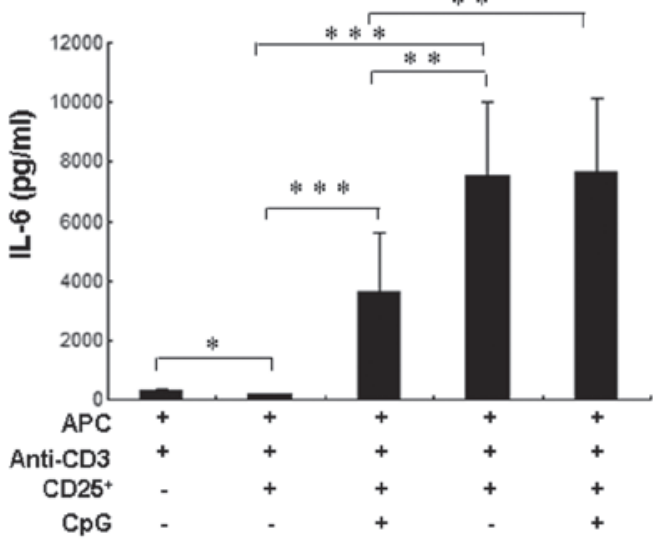

Figure 2. Combination with $\mathrm{CpG}$ induced a panel of proinflammatory cytokines in a conventional in vitro suppression assay. Isolated $\mathrm{CD} 4^{+} \mathrm{CD} 25^{-} \mathrm{T}$ cells (1x10 $/$ well) from naïve rats were cultured with or without CD $4^{+} \mathrm{CD} 25^{+}$Tregs $\left(5 \times 10^{4} /\right.$ well), irradiated APCs (1x10 $/$ well) and $1 \mu \mathrm{g} / \mathrm{ml}$ anti-CD3 in $96-$ well plates in the presence or absence of $3 \mu \mathrm{g} / \mathrm{ml}$ CpG. Supernatants were collected after $72 \mathrm{~h}$ of culture and tested for (A) IFN- $\gamma$, (B) TNF- $\alpha$, (C) IL-4, (D) IL-10, (E) IL-2 or (F) IL-6. Data are expressed as the means \pm standard deviation from two experiments performed in triplicate wells. ${ }^{*} \mathrm{P}<0.05 ;{ }^{* *} \mathrm{P}<0.01 ;{ }^{* * *} \mathrm{P}<0.001$.

Combination with $\mathrm{Cp} G$ induces higher levels of proinflammatory cytokines in a conventional suppression assay in vitro. $\mathrm{CpG}$ was shown to significantly increase the levels of these cytokines in the above-mentioned supernatant. $\mathrm{CpG}$ induced the production of higher IFN- $\gamma$, TNF- $\alpha$, IL-4, IL-2 and IL-6 levels. Compared to IL-10 levels, the secretion of IFN- $\gamma$, TNF- $\alpha$, IL-4, IL-2 and IL- 6 was significantly higher in a conventional in vitro suppression assay following the addition of $\mathrm{CpG}$ (Fig. 2). Thus, these results suggest that the combination with $\mathrm{CpG}$ induced higher levels of proinflammatory cytokines that may help hinder the immunosuppression of $\mathrm{CD} 4{ }^{+} \mathrm{CD} 25^{+}$Tregs in a conventional in vitro suppression assay.

Cp $G$ reduces induction of Foxp3-expressing $T$ cells in vitro. Foxp3 expression was analyzed by flow cytometry, which demonstrated that a significantly reduced percentage of Foxp3-expressing cells were observed among splenocytes in the presence of $\mathrm{CpG}$. $\mathrm{CpG}$ alone induced a reduction in Foxp3 expression which was not statistically significant compared to the medium alone (Fig. 3).

\section{Discussion}

TLR ligands coordinate innate, adaptive and regulatory immune responses and as vaccine adjuvants they represent a promising approach to stimulating strong immune responses and enhancing vaccine-induced protection (17). TLR9 ligands, including $\mathrm{CpG}$, enhance immune responses to co-delivered antigens in animal models and are currently being developed for clinical use as either vaccine adjuvants or immune therapeutics by Coley Pharmaceuticals (Pfizer, New York, NY, USA) and Dynavax Technologies. However, the effect of $\mathrm{CpG}$ on vaccines against schistosomiasis, a disease that poses a significant public health concern in numerous tropical countries, has not been elucidated and was the subject of this investigation. 

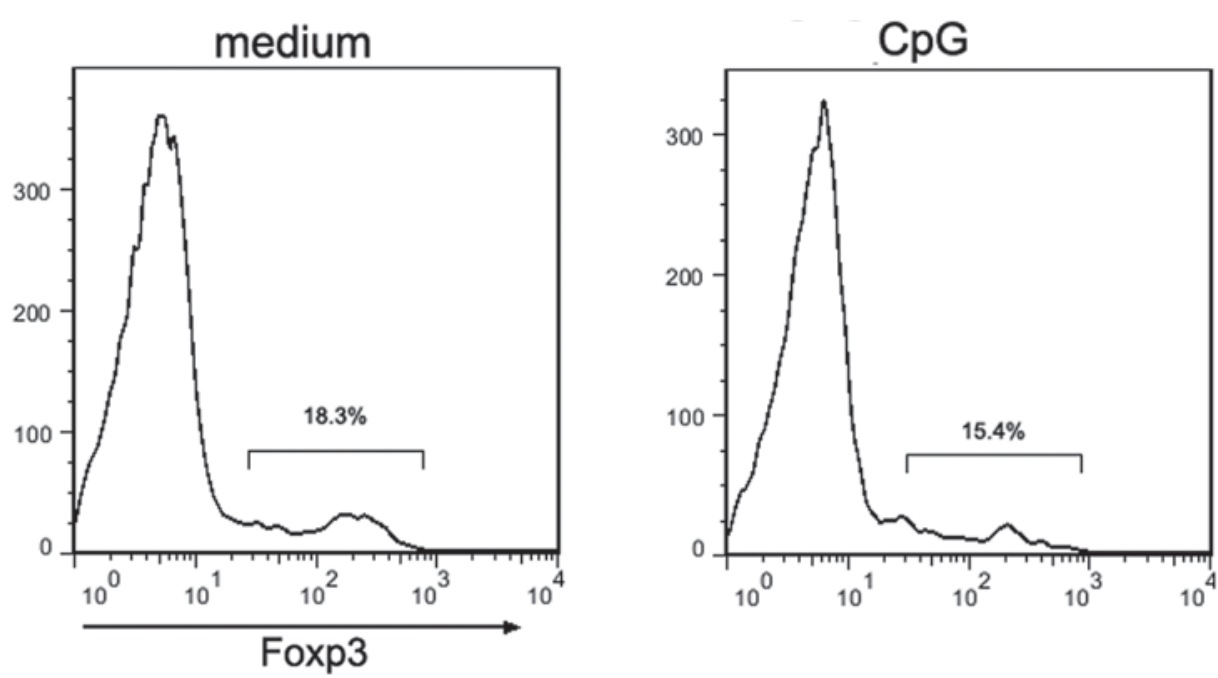

Figure 3. CpG reduced the induction of Foxp3-expressing T cells in vitro. Splenocytes from naïve rats were stimulated in vitro with $3 \mu \mathrm{g} / \mathrm{ml} \mathrm{CpG} \mathrm{for} 48 \mathrm{~h}$ and were then subjected to flow cytometry analysis for Foxp3 expression in $\mathrm{CD} 4^{+} \mathrm{T}$ cells. $\mathrm{P}<0.05$.

In the present study, we demonstrated that immunization with pVAX1-Sj26GST including $\mathrm{CpG}$ as an adjuvant may induce stronger protection compared to pVAX1-Sj26GST alone or single ligands combined. It was reported that TLR ligands as adjuvants may elicit more vigorous immune responses against infection and cancer $(17,18)$. The quantification of cytokines in splenocyte culture supernatants indicated that pVAX1-Sj26GST vaccination induced a significant increase in IFN- $\gamma$ levels and a reduction in IL-4 and IL-10 levels in vaccinated control pVAX-treated rats. However, the combination with $\mathrm{CpG}$ enhanced the production of IFN- $\gamma$ and TNF- $\alpha$, although it also increased the secretion of IL- 4 and IL-10 in rats vaccinated by pVAX1-Sj26GST plus CpG, which, however, remained lower compared to that in pVAX1-vaccinated rats. The elevated IFN- $\gamma$ and TNF- $\alpha$ levels in response to the combination with $\mathrm{CpG}$ may be associated with the enhancement of protection conferred by pVAX1-Sj26GST vaccination since the protection induced by several schistosoma vaccines was associated with elevated production of IFN- $\gamma$ and TNF- $\alpha(19,20)$. Our data also suggested that triggering more than one TLR may be an effective approach to optimize immune responses to vaccination. This finding is consistent with those of several previous studies (21).

There is evidence that TLR signaling may modulate the suppressive functions of Tregs $(22,23)$. It has been suggested that exposure to inflammatory cytokines released by APCs may render Tregs defective in mediating their suppressive effects (24). Furthermore, exposure to TNF may inhibit the function of Tregs by TNF receptor II signaling (25). Consistent with a previous study which reported that $\mathrm{CD} 4^{+} \mathrm{CD} 25^{+}$Tregs are able to suppress T-cell proliferation and cytokine production (26), our study demonstrated that the presence of $\mathrm{CpG}$ in a conventional in vitro suppression assay induced a panel of inflammatory cytokines, including IFN- $\gamma$, TNF- $\alpha$, IL-4, IL-10, IL-2 and IL-6, and these elevated cytokines may inhibit the Treg suppressive function, since a variety of cytokines have been reported to inhibit Treg function in autoimmune reactions, including TNF- $\gamma$, IL-4, IL-6 and IL-12 (27). Although IL-10, as a major anti-inflammatory cytokine induced by TLR signaling, inhibits the production of TLR-induced proinflammatory mediators, such as TNF (13), this study demonstrated that elevated levels of IL-10 in the presence of $\mathrm{CpG}$ in an in vitro suppression assay were insufficient to overcome the strong inflammatory response mediated by the other cytokines.

Furthermore, $\mathrm{CpG}$ reduced the expression of Foxp3 in $\mathrm{CD} 4^{+} \mathrm{T}$ cells in vitro, which is indispensable in Treg development and function. Although the in vitro assays of TLR ligands on Tregs failed to completely mimic the in vivo milieu, they may lead to the hypothesis that the downregulation of Foxp3 expression, not only affects Treg function in vitro, but may also impair Treg generation following vaccination in vivo, thereby reducing the frequency of $\mathrm{CD} 4{ }^{+} \mathrm{CD} 25^{+}$Tregs in rats vaccinated by pVAX1-Sj26GST combined with $\mathrm{CpG}$, since Foxp3 is critical for the development and differentiation of Tregs and transduction of Foxp3 into naïve $\mathrm{CD}^{+} \mathrm{T}$ cells resulted in a suppressive phenotype in rats $(14,28)$. These results are consistent with a previous study that demonstrated that activation of DCs by TLR7 ligands leads to the downregulation of Foxp3 expression following the initial induction and consequently reduces Treg numbers in the DC-T-cell cocultures in vitro. Furthermore, single TLR ligands were less effective in decreasing CD4 ${ }^{+} \mathrm{Foxp} 3^{+} \mathrm{T}$ cells, whereas the combination of TLR ligands may prevent expansion of Foxp $3^{+}$ Tregs, thereby improving T-cell responses (29).

In conclusion, this study has demonstrated that $\mathrm{CpG}$ may impair Treg development and function by upregulating the secretion of pro-inflammatory cytokines. Defective Tregs provide the effector response freedom to generate protective immunity when in combination with the vaccine, in order to elicit the most appropriate immune response in rats.

\section{Acknowledgements}

This study was supported by a grant from the National Natural Science Foundation of China (NSFC nos. 30801046 and 81172778) and the grant KJ2010A087 from the Natural Science Foundation of Anhui Province. 


\section{References}

1. Hotez PJ, Brindley PJ, Bethony JM, King CH, Pearce EJ, et al: Helminth infections: the great neglected tropical diseases. J Clin Invest 118: 1311-1321, 2008.

2. King CH: Toward the elimination of schistosomiasis. N Engl J Med 360: 106-109, 2009.

3. Doenhoff MJ, Cioli D and Utzinger J: Praziquantel: mechanisms of action, resistance and new derivatives for schistosomiasis. Curr Opin Infect Dis 21: 659-667, 2008.

4. Abdul-Ghani R, Loutfy N, el-Sahn A and Hassan A: Current chemotherapy arsenal for schistosomiasis mansoni: alternatives and challenges. Parasitol Res 104: 955-965, 2009.

5. Fenwick A, Webster JP, Bosque-Oliva E, Blair L, Fleming FM, et al: The Schistosomiasis Control Initiative (SCI): rationale, development and implementation from 2002-2008. Parasitology 136: 1719-1730, 2009.

6. McManus DP and Loukas A: Current status of vaccines for schistosomiasis. Clin Microbiol Rev 21: 225-242, 2008.

7. Bergquist NR, Leonardo LR and Mitchell GF: Vaccine-linked chemotherapy: can schistosomiasis control benefit from an integrated approach? Trends Parasitol 21: 112-117, 2005.

8. Aloysius MM, Mc Kechnie AJ, Robins RA, Verma C, Eremin JM et al: Generation in vivo of peptide-specific cytotoxic $\mathrm{T}$ cells and presence of regulatory $\mathrm{T}$ cells during vaccination with hTERT (class I and II) peptide-pulsed DCs. J Transl Med 7: 18, 2009.

9. Toka FN, Suvas S and Rouse BT: $\mathrm{CD} 4^{+} \mathrm{CD} 25^{+} \mathrm{T}$ cells regulate vaccine-generated primary and memory $\mathrm{CD} 8^{+} \mathrm{T}$-cell responses against herpes simplex virus type 1. J Virol 78: 13082-13089, 2004.

10. Wang X, Zhou S, Chi Y, Wen X, Hoellwarth J, et al: CD $4^{+} \mathrm{CD} 25^{+}$ Treg induction by an HSP60-derived peptide SJMHE1 from Schistosoma japonicum is TLR2 dependent. Eur J Immunol 39: 3052-3065, 2009.

11. Tang CL, Lei JH, Wang T, Lu SJ, Guan F, et al: Effect of $\mathrm{CD} 4^{+} \mathrm{CD} 25^{+}$regulatory $\mathrm{T}$ cells on the immune evasion of Schistosoma japonicum. Parasitol Res 108: 477-480, 2010.

12. Ahmad G, Zhang W, Torben W, Noor Z and Siddiqui AA: Protective effects of Sm-p80 in the presence of resiquimod as an adjuvant against challenge infection with Schistosoma mansoni in mice. Int J Infect Dis 14: e781-e787, 2010.

13. Mosser DM and Zhang X: Interleukin-10: new perspectives on an old cytokine. Immunol Rev 226: 205-218, 2008.

14. Schmetterer KG, Neunkirchner A and Pickl WF: Naturally occurring regulatory T cells: markers, mechanisms, and manipulation. FASEB J 26: 2253-2276, 2012.

15. LaRosa DF, Gelman AE, Rahman AH, Zhang J, Turka LA and Walsh PT: $\mathrm{CpG}$ DNA inhibits $\mathrm{CD} 4^{+} \mathrm{CD} 25^{+}$Treg suppression through direct MyD88-dependent costimulation of effector CD4 ${ }^{+}$T cells. Immunol Lett 108: 183-188, 2007.
16. Peng G, Guo Z, Kiniwa Y, Voo KS, Peng W, et al: Toll-like receptor 8-mediated reversal of $\mathrm{CD}^{+}{ }^{+}$regulatory $\mathrm{T}$ cell function. Science 309: 1380-1384, 2005.

17. Duthie MS, Windish HP, Fox CB and Reed SG: Use of defined TLR ligands as adjuvants within human vaccines. Immunol Rev 239: 178-196, 2011.

18. Engel AL, Holt GE and Lu H: The pharmacokinetics of Toll-like receptor agonists and the impact on the immune system. Expert Rev Clin Pharmacol 4: 275-289, 2011.

19. Farias LP, Cardoso FC, Miyasato PA, Montoya BO, Tararam CA, et al: Schistosoma mansoni Stomatin like protein-2 is located in the tegument and induces partial protection against challenge infection. PLoS Negl Trop Dis 4: e597, 2010.

20. Cardoso FC, Macedo GC, Gava E, Kitten GT, Mati VL, et al: Schistosoma mansoni tegument protein $\mathrm{Sm} 29$ is able to induce a Th1-type of immune response and protection against parasite infection. PLoS Negl Trop Dis 2: e308, 2008.

21. Napolitani G,Rinaldi A,Bertoni F, Sallusto F and Lanzavecchia A: Selected Toll-like receptor agonist combinations synergistically trigger a $\mathrm{T}$ helper type 1-polarizing program in dendritic cells. Nat Immunol 6: 769-776, 2005.

22. Liu G and Zhao Y: Toll-like receptors and immune regulation: their direct and indirect modulation on regulatory $\mathrm{CD} 4^{+} \mathrm{CD} 25^{+}$ T cells. Immunology 122: 149-156, 2007.

23. Walker LS: Regulatory T cells overturned: the effectors fight back. Immunology 126: 466-474, 2009.

24. Andre S, Tough DF, Lacroix-Desmazes S, Kaveri SV and Bayry J: Surveillance of antigen-presenting cells by $\mathrm{CD} 4{ }^{+} \mathrm{CD} 25^{+}$ regulatory $\mathrm{T}$ cells in autoimmunity: immunopathogenesis and therapeutic implications. Am J Pathol 174: 1575-1587, 2009.

25. Valencia X, Stephens G, Goldbach-Mansky R, Wilson M, Shevach EM, et al: TNF downmodulates the function of human CD4 ${ }^{+} \mathrm{CD} 25$ hi T-regulatory cells. Blood 108: 253-261, 2006.

26. Sakaguchi S, Wing K, Onishi Y, Prieto-Martin P and Yamaguchi T: Regulatory T cells: how do they suppress immune responses? Int Immunol 21: 1105-1111, 2009.

27. Buckner JH: Mechanisms of impaired regulation by CD4(+) CD25(+)FOXP3(+) regulatory $\mathrm{T}$ cells in human autoimmune diseases. Nat Rev Immunol 10: 849-859, 2010.

28. Lu LF and Rudensky A: Molecular orchestration of differentiation and function of regulatory T cells. Genes Dev 23: 1270-1282, 2009.

29. Zhu Q, Egelston C, Gagnon S, Sui Y, Belyakov IM, et al: Using 3 TLR ligands as a combination adjuvant induces qualitative changes in $\mathrm{T}$ cell responses needed for antiviral protection in mice. J Clin Invest 120: 607-616, 2010. 